\title{
Study on the Static Performance of Prefabricated UHPC-Steel Epoxy Bonding Interface
}

\author{
Yang Zou $\mathbb{D}^{1},{ }^{1}$ Jinlong Jiang, ${ }^{1}$ Zhixiang Zhou $\mathbb{D}^{2},{ }^{2}$ Xifeng Wang, ${ }^{1}$ and Jincen Guo ${ }^{1,2}$ \\ ${ }^{1}$ State Key Laboratory of Mountain Bridge and Tunnel Engineering, Chongqing Jiaotong University, Chongqing 400074, China \\ ${ }^{2}$ Department of Civil Engineering, School of Civil and Transportation Engineering, Shenzhen University, Shenzhen 518060, China
}

Correspondence should be addressed to Zhixiang Zhou; zhixiangzhou@szu.edu.cn

Received 30 November 2020; Revised 22 December 2020; Accepted 5 January 2021; Published 21 January 2021

Academic Editor: Zhigang Zhang

Copyright (c) 2021 Yang Zou et al. This is an open access article distributed under the Creative Commons Attribution License, which permits unrestricted use, distribution, and reproduction in any medium, provided the original work is properly cited.

Prefabricated UHPC-steel composite structure can make full use of the two materials' mechanical and construction performance characteristics, with super mechanical properties and durability, which has been proved to be a very promising structure. However, using traditional mechanical connectors to connect prefabricated UHPC and steel not only is inconvenient for the prefabrication of UHPC components but also introduces heavy welding work, which is detrimental to the construction speed and antifatigue performance of the composite structure. Bonding UHPC-steel interface with epoxy adhesive is a potential alternative to avoid the above problem. In order to explore the mechanical properties of the prefabricated UHPC-steel epoxy bonding interface, this study carried out the direct shear test, tensile test, and tensile-shear test of the UHPC-steel epoxy-bonded interface (prefabricated UHPC-steel epoxy bonding interface). The results show that the interface failure is mainly manifested as the peeling of the epoxy-UHPC interface and the destruction of part of the UHPC matrix (the failure of the UHPC's surface). In pure shear and pure tension state, the interfacial shear strength is $5.14 \mathrm{MPa}$ and the interfacial tensile strength is $1.18 \mathrm{MPa}$. In the tensile-shear state, the interfacial shear strength is $0.61 \mathrm{MPa}$ and the interfacial tensile strength is $1.06 \mathrm{MPa}$. The stress-displacement curves of the interface normal and tangential direction are all in the shape of a two-fold line. The ultimate displacement was within $0.1 \mathrm{~mm}$, showing the characteristics of brittle failure. Finally, a numerical model of the tensile specimen is established based on the cohesive interface element, and the interfacial tensile-shear coupling failure mechanism (tensile-shear coupling effect) is analyzed.

\section{Introduction}

Ultrahigh performance concrete (UHPC), as a new type of steel fiber reinforced concrete, is usually composed of cement, silica powder, quartz sand, fiber, high-efficiency water reducer, and other components. Compared with standard concrete, UHPC has more excellent tensile, compressive strength (usually) higher than $150 \mathrm{MPa}$ compressive strength, tensile strength is greater than $8 \mathrm{MPa}$ [1], high ductility [2], and excellent durability [3]. It has been widely used in civil engineering and has been proved to be a new civil engineering material with excellent application prospects [4-6]. Like engineering cement composite (ECC), UHPC has been proved to be a new civil engineering material with excellent application prospects [4-6].
For the general concrete, the surface is easy to crack; poor durability has been an unavoidable problem. Therefore, to improve the crack resistance and durability of concrete, engineering cement composite materials (ECC) and ultrahigh performance concrete (UHPC) have been widely used in recent years. ECC has high ductility [7], self-healing properties [8], and good impact resistance [9], with a tensile strain capacity of over $3 \%$. As a new type of steel fiber reinforced concrete, UHPC is usually composed of cement, silica powder, quartz sand, fiber, high-efficiency water reducer, and other components [10].UHPC has excellent tensile and compressive strength (generally higher than $150 \mathrm{MPa}$ and greater than $8 \mathrm{MPa}$ [1]), high ductility [2], and excellent durability [3]. Like engineering cement composites (ECC), UHPC has been proven to be a new type of civil 
engineering material $[4-6,11,12]$ with great potential for application.

However, there are some problems in the application of UHPC. For example, the spontaneous shrinkage rate of UHPC can reach 500-1500 $\mu \varepsilon$ [13] in the hardening process of UHPC, and shrinkage cracks appear easily when the shrinkage is constrained. At the same time, the performance of UHPC is also significantly affected by curing conditions. These characteristics limit the complete application of UHPC in the way of cast-in-place, and the use of UHPC precast components can avoid the above problems [14-16]. Because of the controllable curing conditions in the prefabrication plant and the absence of external constraints, precast UHPC members' shrinkage will not cause cracking. In the steel-concrete composite bridge, the use of UHPC can improve the anticrack performance of the bridge deck and reduce the dead weight of the deck $[17,18]$. However, the reliable connection between the steel beam and the bridge deck significantly affects the composite effect $[19,20]$. Like the traditional steel-concrete composite structure, the connection between UHPC and steel beam is usually realized by mechanical connectors such as studs. Many studs are arranged on the steel beam to ensure a reliable connection at the interface [21]. In this connection mode, welding defects and residual stresses are inevitably introduced in stud welding, which is unfavorable to steel structure fatigue. Meanwhile, when UHPC is used as a structural layer of orthotropic steel deck, the number of studs on a single bridge deck may exceed millions, which brings heavy welding work [22]. Secondly, when the stud is used to connect the precast deck and steel beam, many holes need to be reserved on the precast deck, which brings inconvenience to the fabrication of the deck. Therefore, scholars and engineers are also trying to bond the interface between steel and concrete by adhesive [23-25]. The results show that the epoxy bonding method can realize the reliable connection between the two materials and avoid the stress concentration caused by mechanical connectors, which is beneficial to the steel structure's fatigue performance. Simultaneously, the epoxy bonding method can significantly reduce the studs' welding workload, accelerating the construction speed.

Larbi et al. [26] conduct shear and tensile tests on 11(eleven) steel-concrete interface specimens and find that when the specimens are loaded in a single direction, the normal and tangential ultimate stresses at the epoxy-bonded interface are $3.5 \mathrm{MPa}$ and $6.4 \mathrm{MPa}$, respectively. Under the bidirectional loading condition, the shear and tensile ultimate stresses at the interface follow the quadratic relation. Berthet et al. [27] design the natural bond and epoxy bond interface between steel and concrete and find that the shear strength of the natural bond interface and the epoxy bond interface is $0.8 \mathrm{MPa}$ and $3.4 \mathrm{MPa}-5.4 \mathrm{MPa}$, which are greater than the shear strength of the concrete. Q.Sun et al. [28] spread limestone evenly after applying epoxy adhesive on the steel plate and carry out the tensile test and push-out test on this interface form. The test results show that the UHPCsteel plate interface leads to high bonding performance under the pure tension and pure shear state of normal and tangential direction. Its tensile and shear strength reaches about $2 \mathrm{MPa}$, but its interface state is a brittle failure under the unconstrained state. Wang et al. [29] conduct bending tests on UHPC- steel composite beams with different interfaces and obtain that the ultimate load of beam LEA-6.9 is 93.2\% of that of beam LHS-6.9. The beam LHS6.9 adopts epoxy adhesive sprinkled with limestone aggregate for interface treatment, while the latter adopts studs. The interface adopting epoxy adhesive and limestone aggregate can successfully replace the shear stud interface to some extent. Luo et al. [25] carried out corresponding research on UHPCpaved steel bridge deck structure and compared with the steel mesh welded to the steel bridge deck; it was found that the epoxy bonding and rough treatment between the interfaces can avoid the phenomenon of stress concentration. When the interface is subjected to normal tension, the bond strength is $3 \sim 5 \mathrm{MPa}$; when the bridge deck is flexural, the interfacial shear strength is $11-13 \mathrm{MPa}$. These studies show that the shear strength of the steel-precast concrete interface [26] is different from that of the steel in-situ concrete interface [27], but the shear strength is between 5 and $6 \mathrm{MPa}$. However, the research mentioned above on UHPC-steel epoxy bonding interface properties are all carried out for cast-in-place UHPC. Therefore, this paper focuses on the prefabricated UHPC-steel epoxy bonding interface's static performance to provide a reference for the prefabricated UHPC-steel composite bridge using epoxy adhesive.

In order to explore the mechanical properties of the prefabricated UHPC-steel interface with epoxy adhesive, the failure modes, bonding strength, and stress-displacement curves of the prefabricated UHPC-steel epoxy bonding interface were determined through the direct shear test, axial tensile test (tensile test), and tensile-shear test. The constitutive model of the prefabricated UHPC-steel epoxy bonding interface was constructed based on the constitutive cohesion model of the bilinear tension-displacement (traction-separation) relationship.

\section{Interface Test}

2.1. Specimen Design. The details of the specimens were shown in Table 1 and Figure 1. In the direct shear test, to avoid eccentric loading, the thickness of the specimen's steel plate (PS-E) within $50 \mathrm{~mm}$ from the loading end was increased by $5 \mathrm{~mm}$ so that the loading point can be controlled in the plane where the interface was located. The specific size of the specimen is shown in the figure. In the axial tensile test(tensile test), the specimen (PT-E) had a loaded steel plate size of $150 \mathrm{~mm} \times 150 \mathrm{~mm} \times 20 \mathrm{~mm}$, and ribbed rebars with a diameter of $12 \mathrm{~mm}$ were welded on the steel plate. The adhesive area of the specimen PS-E and the specimen PT-E was $150 \mathrm{~mm} \times 150 \mathrm{~mm}$. In the tensileshear test, the size of the steel plate of the specimen (ST-E) was $150 \mathrm{~mm} \times 144 \mathrm{~mm} \times 20 \mathrm{~mm}$, and there were six ribbed rebars with a diameter of $8 \mathrm{~mm}$ welded on the surface to ensure the reliable connection with UHPC on the other side of the interface. The two ends of the specimen transmitted tensile force through rebars with a diameter of $12 \mathrm{~mm}$. 
TABle 1: Detailed information of the specimen.

\begin{tabular}{lcccc}
\hline Specimen & Interface size $(\mathrm{mm})$ & Interface & thickness $(\mathrm{mm})$ & Interface tilt angle $\alpha$ \\
PS-E & $150 \times 150$ & 2 & - & Number \\
PT-E & $150 \times 150$ & 2 & - & 6 \\
ST-E & $144 \times 150$ & 2 & $30^{\circ}$ & 6 \\
\hline
\end{tabular}

Note. Interface tilt angle $\alpha$ is listed in Figure 1(i).

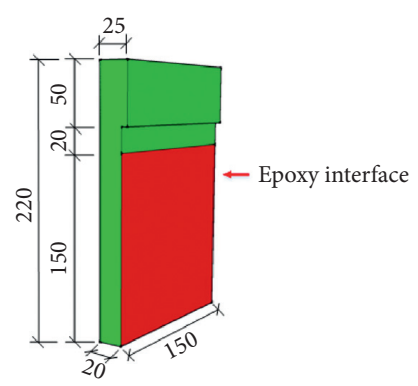

(a)

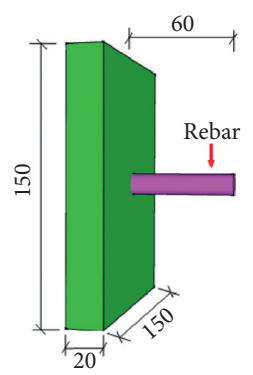

(d)

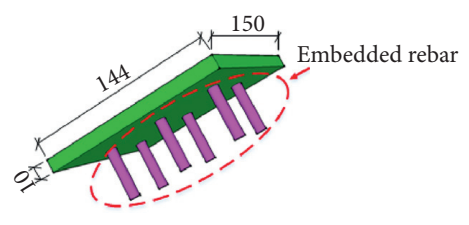

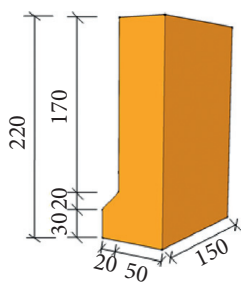

(b)

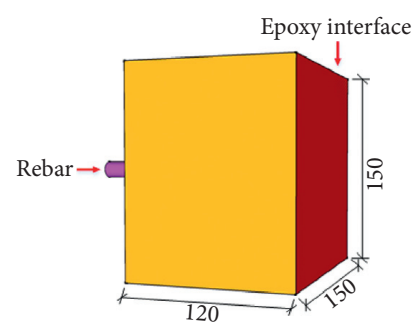

(e)

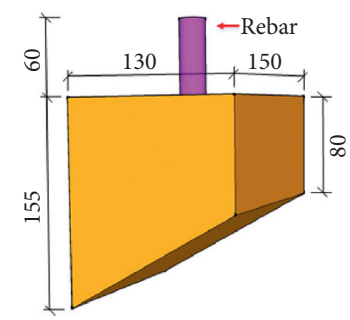

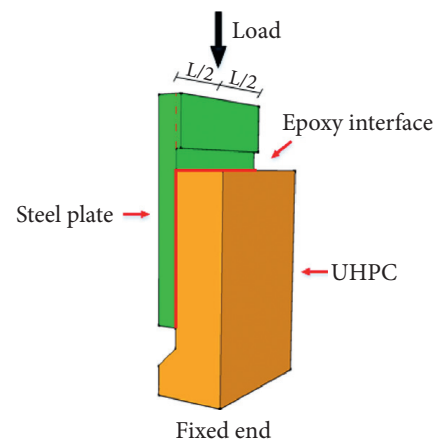

(c)

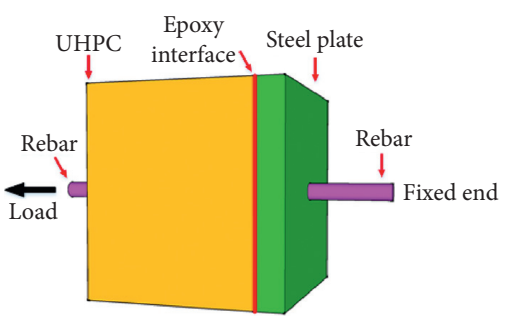

(f)

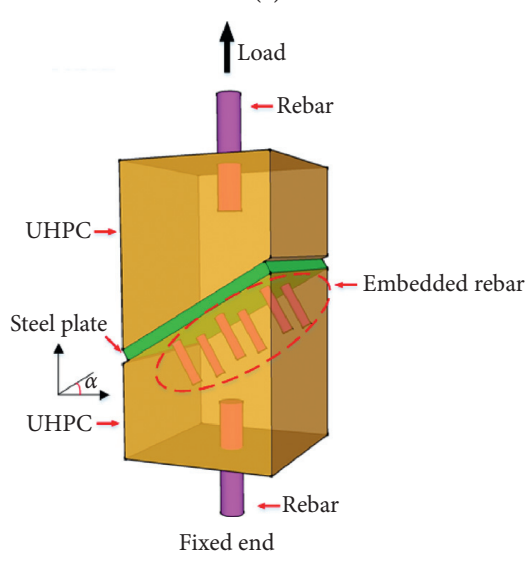

(i)

FIGURE 1: Detailed information of specimen: ( $a, b$, and c) Components and overall structure of specimen PS-E; (d, e, and f) Components and overall structure of specimen PT-E; (g, h, and f) Components and overall structure of ST-E (unit: mm). (a) Steel plate. (b) UHPC. (c) Specimen PS-E. (d) Steel plate. (e) UHPC. (f) Specimen PT-E. (g) Steel plate. (h) UHPC. (i) Specimen ST-E.

2.2. Material Properties. The specific mix proportion of UHPC is shown in Table 2. Among them, the steel fiber doped in UHPC is straight, $8 \mathrm{~mm}$ in length, $0.12 \mathrm{~mm}$ in diameter, and $2 \%$ in volume.

The epoxy resin used in this test is CBSR-A/B steel adhesive produced by Carbon Technology Group Co., Ltd., which mainly consists of primary agent CBSR-A and curing agent CBSR-B, with the material weight ratio of $2: 1$. The tensile strength, compressive strength, and flexural strength of epoxy adhesive are $30 \mathrm{MPa}, 65 \mathrm{MPa}$, and $45 \mathrm{MPa}$, respectively, and the tensile elastic modulus is $3200 \mathrm{MPa}$.

The mechanical properties of steel plate, rebar, and UHPC are shown in Tables 3 and 4, respectively. 
TABLE 2: Specific mix proportion of UHPC.

\begin{tabular}{lcc}
\hline Component & Mass ratio & Proportion (\%) \\
\hline Cement & 1.000 & 34.55 \\
Silica fume & 0.250 & 8.64 \\
Quartz sand & 1.100 & 38.01 \\
Quartz flour & 0.300 & 10.37 \\
Water- reducing agent & 0.019 & 0.66 \\
Water & 0.225 & 7.77 \\
\hline
\end{tabular}

TABLE 3: Mechanical properties of steel plate and rebar.

\begin{tabular}{|c|c|c|c|c|c|c|}
\hline Part & Category & Thickness (mm) & $f_{s}(\mathrm{MPa})$ & $f_{s u}(\mathrm{MPa})$ & $E_{s}(\mathrm{MPa})$ & $\overline{v_{s}}$ \\
\hline \multirow{3}{*}{ Steel plate } & \multirow{3}{*}{ Interface plate } & 20 & 215 & 350 & \multirow{3}{*}{$\begin{array}{c}206000 \\
E_{r s}(\mathrm{MPa})\end{array}$} & \multirow{3}{*}{0.3} \\
\hline & & 10 & 225 & 370 & & \\
\hline & & Diameter (mm) & $f_{y}(\mathrm{MPa})$ & $f_{u}(\mathrm{MPa})$ & & \\
\hline Rebar & $\begin{array}{l}\text { Drawing rebar } \\
\text { Embedded rebar }\end{array}$ & $\begin{array}{c}12 \\
8\end{array}$ & 345 & 377 & 210000 & 0.3 \\
\hline
\end{tabular}

Note: $f_{s}$ is the yield strength of steel plate; $f_{s u}$ is the ultimate strength of steel plate; $E_{s}$ is Young's modulus of steel plate; $v_{s}$ is Poisson's ratio of steel plate; $f_{y}$ is the yield strength of rebar; $f_{u}$ is the ultimate strength of rebar; $E_{r s}$ is Young's modulus of rebar; $v_{r s}$ is Poisson's ratio of rebar.

TABLE 4: Mechanical properties of UHPC.

\begin{tabular}{lcccc}
\hline Part & $f_{c}(\mathrm{MPa})$ & $f_{c t}(\mathrm{MPa})$ & $E_{c}(\mathrm{MPa})$ & $v_{c}$ \\
\hline UHPC & 112 & 20 & 42100 & 0.2 \\
\hline
\end{tabular}

Note: $f_{c}$ is the compressive strength of UHPC; $f_{\mathrm{ct}}$ is flexural strength of UHPC; $E_{c}$ is Young's modulus of UHPC; $v_{c}$ is Poisson's ratio of UHPC.

2.3. Loading Scheme. An electronic universal testing machine (MTS Exceed E45.205) was used to carry out the direct shear test, tensile test, and tensile-shear test on specimen PSE, specimen PT-E, and specimen ST-E, respectively. As shown in Figure 2, two dial indicators were arranged symmetrically at both ends of each specimen's interface, and the measured interface displacement was the average value of the data in the dial indicator. All tests adopted the displacement loading control method, and the loading speed was $0.01 \mathrm{~mm} / \mathrm{min}$ until the specimen was damaged by loading.

\section{Analysis of Test Results}

3.1. Direct Shear Test. At the initial loading stage, a weak crackling sound began to be emitted intermittently at the interface in the direct shear test. At this time, there was no apparent interface displacement or surface cracking of UHPC. Then, as the ultimate bearing capacity approaches, partial disengagement was observed at the interface. After the ultimate bearing capacity was reached, the interface suddenly cracks, and the bearing capacity of the specimen is lost instantly. Take the specimens PS-E-3 and PS-E-6 as examples; see Figure 3, for the steel plate interface and UHPC after breakage.

In the direct shear test, there were several types of failure modes for the prefabricated UHPC-steel epoxy bonding interface: E-S interface failure, E-U interface failure, and localized failure of the epoxy layer. It can be observed that, after the specimen PS-E-6 was destroyed, the interface bonding area can be divided into zone I and zone II. Zone I showed the peeling in the E-U interface, and the peeling in the E-S interface was concentrated in zone II. Apart from the cracking boundary formed by these two interface failures in the epoxy layer, there was no local failure in the epoxy layer. After the failure of specimen PS-E-3, the failure modes of E-S interface failure and E-U interface failure (Zone III and Zone IV) were observed, accompanied by local failure of the epoxy layer. By analyzing the interface failure of all direct shear specimens (PS-E), it can be concluded that the failure modes of the prefabricated UHPC-steel epoxy bonding interface are mainly E-S interface failure and E-U interface failure. Furthermore, because of the excellent bonding properties of UHPC, the area of zone I is larger than that of zone II; that is, the interfacial failure is more concentrated in the E-U interface.

3.2. Tensile Test. In the tensile test, before the ultimate bearing capacity was reached, the measured data of the dial indicator at both ends showed that the relative displacement between the steel plate and UHPC on both sides of the interface was within $0.005 \mathrm{~mm}$, with almost no relative separation displacement and no evident phenomenon during the loading process. When loading to the ultimate bearing capacity, a cracking sound was heard from the interface, and cracking cracks had appeared all around it Figure 4(a). Relatively small separation displacement occurs between the steel plate and UHPC on both sides of the interface. Significantly, the stress-displacement curve near the ultimate bearing capacity has a local surge, but the duration is transient. This phenomenon may be caused by the sudden pulling out of the steel fibers in the UHPC area near the interface and the uneven distribution of interface stress caused by the rebars' failure at both ends to pair completely. Finally, the interface suddenly cracked, and the specimen lost its bearing capacity instantly. Figures 4(b) and 4(c) showed the interface breaking of specimen PT-E-1 during loading and the interface state after a failure. 

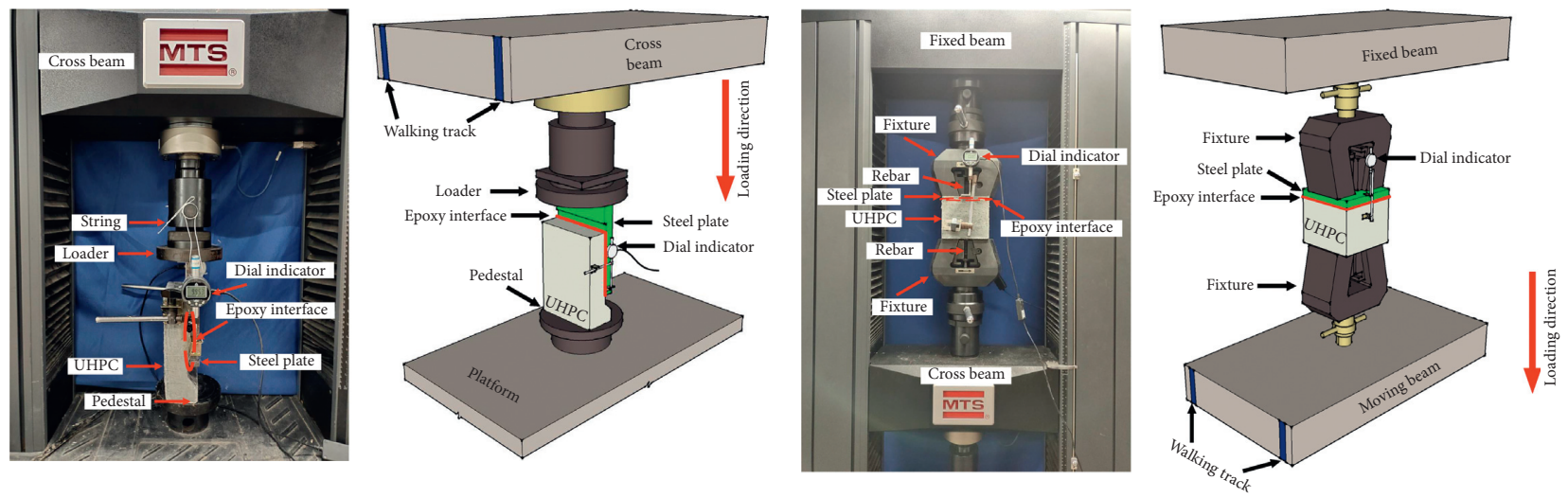

(a)

(b)
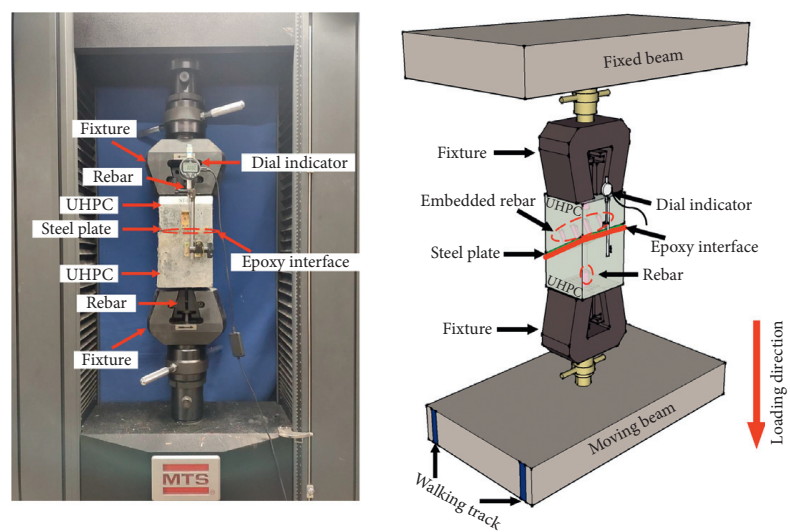

(c)

Figure 2: Loading scheme of specimen PS-E, specimen PT-E, and specimen ST-E. (a) Direct shear test. (b) Tensile test. (c) Tensile-shear test.

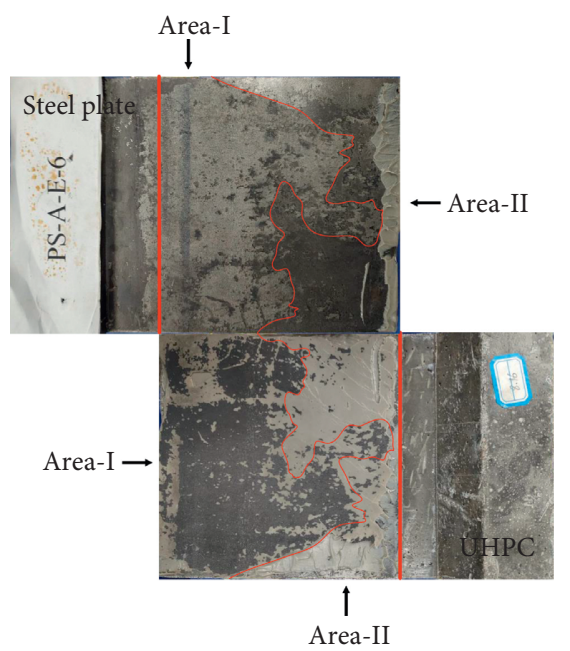

(a)

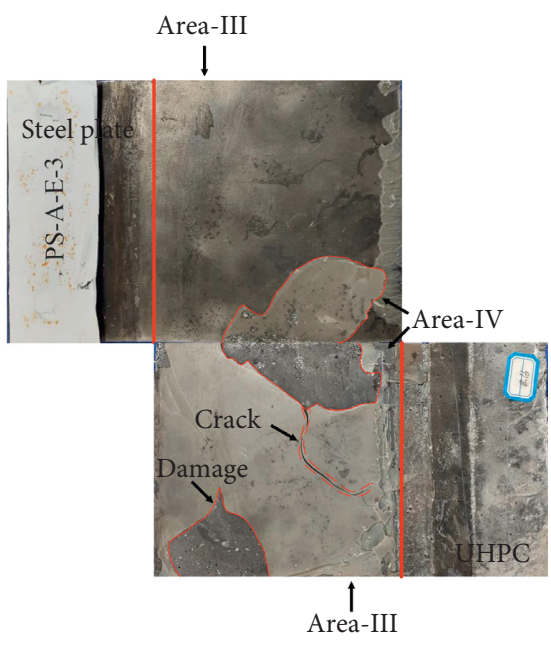

(b)

FIGURE 3: Interface failure mode of specimen PS-E. (a) Epoxy-steel interface failure (E-S interface failure) and epoxy-UHPC interface failure (E-U interface failure). (b) Epoxy-steel interface failure (E-S interface failure), epoxy-UHPC interface failure(E-U interface failure), and epoxy layer's localized failure.

As shown in Figures 4(b) and 4(c), the interface failure of the specimen PT-E occurred on the E-U interface and the UHPC surface near the interface, which was characterized as follows. (1) The surface failure of the UHPC: the area surrounded by dashed lines in the figure was the primary damaged area on the UHPC surface. In this area, the 


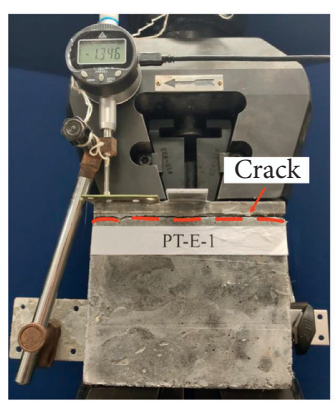

(a)

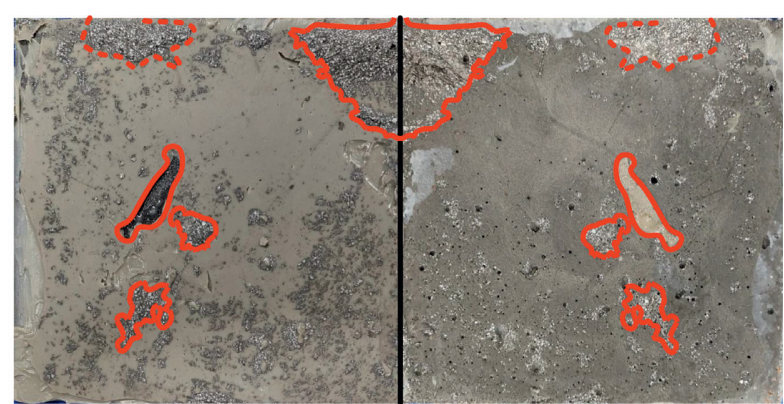

(c)

FIgURE 4: Cracking interface and failure interface of specimen PT-E during loading. (a) Cracking interface; (b) and (c) steel plate and UHPC interface.

bonding property between the epoxy and UHPC surface surfaces was great, and a part of steel fiber and fine aggregate on the UHPC surface was bonded to the surface of the epoxy layer. Except for the delineated area, this failure pattern is distributed throughout the whole interface. (2) E-U interface failure; the interface failure did not damage the epoxy layer and the UHPC surface itself, which was manifested as peeling in the E-U interface, and the epoxy layer and the UHPC surface were free of impurities. (3) Epoxy layer failure: in the area surrounded by the solid line in the figure, the epoxy layer was separated from the steel plate's contact surface, and the broken epoxy adhesive was attached to the UHPC surface. It should be noted that the failure of the rebars at both ends of the specimen to be entirely in alignment would result in the decrease of the tensile strength of the interface, and the test results underestimated the bearing capacity of the specimen. In conclusion, all the tensile specimen (PT-E) test results showed that the interface failure mainly presented the first two failure characteristics.

3.3. Tensile-Shear Test. When the load reached the ultimate bearing capacity in the tensile-shear test, the overall displacement increased significantly compared with the direct shear test and tensile test. The relative separation displacement (in the dial indicator) was about $0.3 \mathrm{~mm}$. After reaching the ultimate bearing capacity, the interface suddenly is broken down, and it lost the bearing capacity instantly, in which relative separation displacement (in the dial indicator) increased to about $0.33 \mathrm{~mm}$. The failure of all specimens was generally characterized by brittle failure. Take specimen ST-E-3, for example, the steel plate interface and UHPC after failure were shown in Figure 5.

In the tensile-shear test, the six specimens' interface failure characteristics are shown in Figure 5. With the epoxy layer as the boundary, the epoxy layer itself was not damaged. The interface failure was concentrated on the UHPC side, mainly manifested as the UHPC surface's damage and the peel in the E-U interface.

3.4. Interfacial Bond Strength. In order to test the bonding strength of the prefabricated UHPC-steel epoxy bonding interface, direct shear test, tensile test, and tensile-shear test are designed, respectively, in this study. Under the action of unidirectional loading, it is necessary to study the bond strength of interface normal and tangential direction by specific evaluation methods. In the direct shear test, the interface is in the state of tangential shear. According to existing literature [30], the interface shear strength of specimens can be defined as follows:

$$
\tau_{t b}=\frac{P_{t}}{A_{t}}
$$

where $P_{t}$ is the load applied during interface shear failure and $A_{t}$ is the bonding interface area.

In the tensile test, the interface is in a normal tension state. According to the existing literature [28], the interfacial tensile strength of specimens can be defined as follows:

$$
\sigma_{n b}=\frac{P_{n}}{A_{n}}
$$

where $P_{n}$ is the load applied during interface tensile failure and $A_{n}$ is the bonding interface area.

In the tensile-shear test, the epoxy bonding interface bears the combined action of normal tension and tangential shear [31], and the bond strength of interface normal and tangential direction is calculated as follows:

$$
\begin{aligned}
\sigma_{n b} & =\frac{P}{A} \cos ^{2} \alpha, \\
\tau_{t b} & =\frac{P}{A} \sin \alpha \cos \alpha,
\end{aligned}
$$

where $\alpha$ is the angle between the interface and the vertical direction of loading, as shown in Figure 1(i), $P$ is the tensile load of the specimen, And $A$ is the cross-sectional area of the specimen.

The test results are summarized in Table 5. In the table, the load value is measured by the load sensor, and the displacement value is the average value of the dial indicator at both ends. Due to the influence of partial void in the interface of the specimen and the failure of the rebar at both ends to completely influence the eccentric loading, the average difference between the bearing capacity of some specimens in the three types of tests and that of other specimens is more than $15 \%$. The experimental data shall not be considered. 


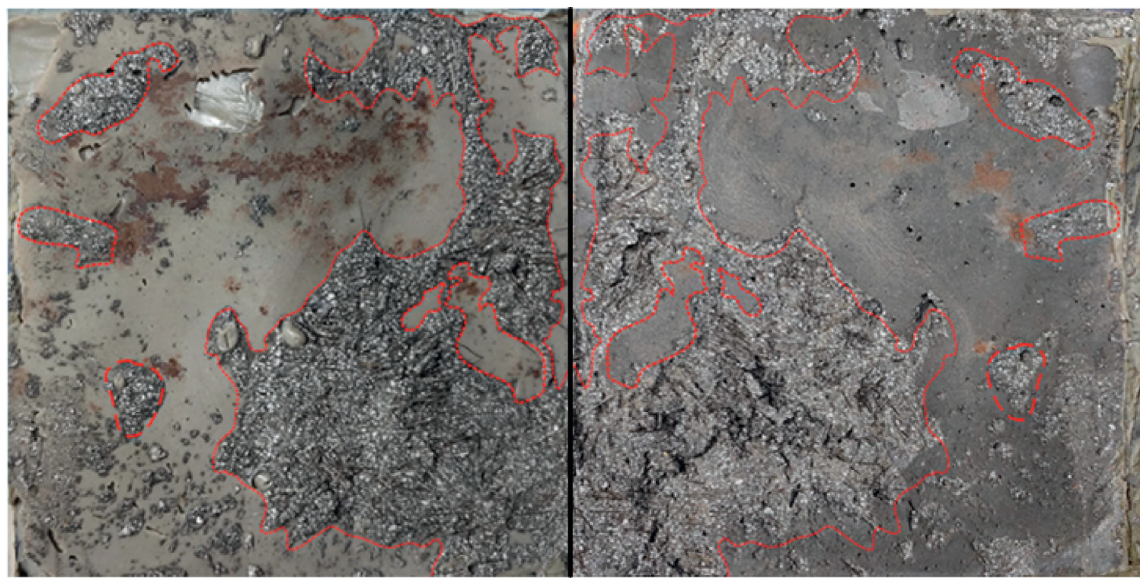

(a)

(b)

FIgURE 5: The interface failure of specimen ST-E. (a) Steel plate. (b) UHPC interface.

Table 5: Test results.

\begin{tabular}{|c|c|c|c|c|c|c|}
\hline Test & Specimen number & $P(\mathrm{kN})$ & $\sigma_{n b}(\mathrm{MPa})$ & $\tau_{t b}(\mathrm{MPa})$ & $\delta_{b}(\mathrm{~mm})$ & $\delta_{p}(\mathrm{~mm})$ \\
\hline \multirow{4}{*}{ Direct shear test } & PS-E-1 & 107.43 & 0 & 4.77 & 0.051 & 0.054 \\
\hline & PS-E-2 & 126.81 & 0 & 5.64 & 0.042 & 0.058 \\
\hline & PS-E-3 & 124.81 & 0 & 5.55 & 0.039 & 0.051 \\
\hline & PS-E-5 & 103.60 & 0 & 4.60 & 0.037 & 0.048 \\
\hline \multirow{4}{*}{ Tensile test } & PT-E-1 & 23.06 & 1.23 & 0 & 0.005 & 0.006 \\
\hline & PT-E-4 & 25.46 & 1.36 & 0 & 0.005 & 0.006 \\
\hline & PT-E-5 & 20.19 & 1.08 & 0 & 0.005 & 0.006 \\
\hline & PT-E-6 & 19.49 & 1.04 & 0 & 0.005 & 0.006 \\
\hline \multirow{4}{*}{ Tensile-shear test } & ST-E-2 & 27.91 & 0.93 & 0.54 & 0.306 & 0.316 \\
\hline & ST-E-3 & 30.14 & 1.00 & 0.58 & 0.326 & 0.347 \\
\hline & ST-E-4 & 37.18 & 1.24 & 0.72 & 0.304 & 0.316 \\
\hline & ST-E-6 & 32.04 & 1.07 & 0.62 & 0.320 & 0.322 \\
\hline
\end{tabular}

Note: $P$ is the ultimate bearing capacity of various specimens before failure; $\sigma_{n b}$ is the normal tensile strength of the interface before the failure of various specimens, the subscript $n$ represents the normal interface direction and $b$ represents that the specimen is in the ultimate loading state; $\tau_{t b}$ is the tangential tensile strength of the interface before the failure of various specimens, the subscript $t$ represents the tangential interface direction, and $b$ represents that the specimen is in the ultimate loading state; $\delta_{b}$ is the displacement value corresponding to the ultimate bearing capacity $P$; $\delta_{p}$ is the ultimate displacement of various specimens(in particular, the displacement in the tensile-shear test is the average value of the dial indicator data).

3.5. Stress-Displacement Curve. In the test design, the relative displacement of the steel plate and UHPC near the interface was the average value of the two dial indicators' data. The load applied to the specimen was obtained by the sensor. Under a pure tension and pure shear state, the interface subjected normal stress, and tangential stress can be obtained from the formula calculated in Section 3.4. Here, the stress-displacement curve of various specimens' interface in the direct shear test and tensile test can be obtained Figure 6. As shown in Figure 7, under the combined action of shear and tensile stresses, the interface normal and tangential stresses of various specimens in the tensile-shear test can be calculated from equations (3) and (4).

Figure 6(a) listed the shear stress-displacement curves of specimen PS-E-1, PS-E-2, PS-E-3, and PS-E-5. Among them, the shear stress-displacement curve of each specimen was in the form of two broken lines. When loading to the ultimate load, no yield platform appeared in these curves, indicating that the epoxy adhesive interface's tangential failure had no ductility. Based on each specimen's ultimate shear stress, the whole curve can be divided into the loading zone and failure zone. In the loading zone, when the shear stress was less than $0.38 \mathrm{MPa}$, there was no displacement in the tangential direction of each specimen interface, and no cracks developed in the interface. With the increase of shear stress, the interface displacement also kept increasing, and the curve was approximate to a linear growth relationship. To define the essential characteristics of the shear stress-displacement curve of this kind of interface, the ultimate shear stress and the corresponding tangential displacement value were the average values of the test results of each specimen in Table 5 , and the calculated coefficient of variation is $8.9 \%$, which was less than $15 \%$. When the shear strain reached the peak value, the shear stress in the failure zone immediately decreased to the interface's loss of bearing capacity, and the interface failure was brittle. The ultimate displacement value is the average value of each specimen's ultimate tangential displacement in Table 5.

Figure 6(b) showed the tensile stress-displacement curves of specimen PT-E-1, PT-E-4, PT-E-5, and PT-E-6. 


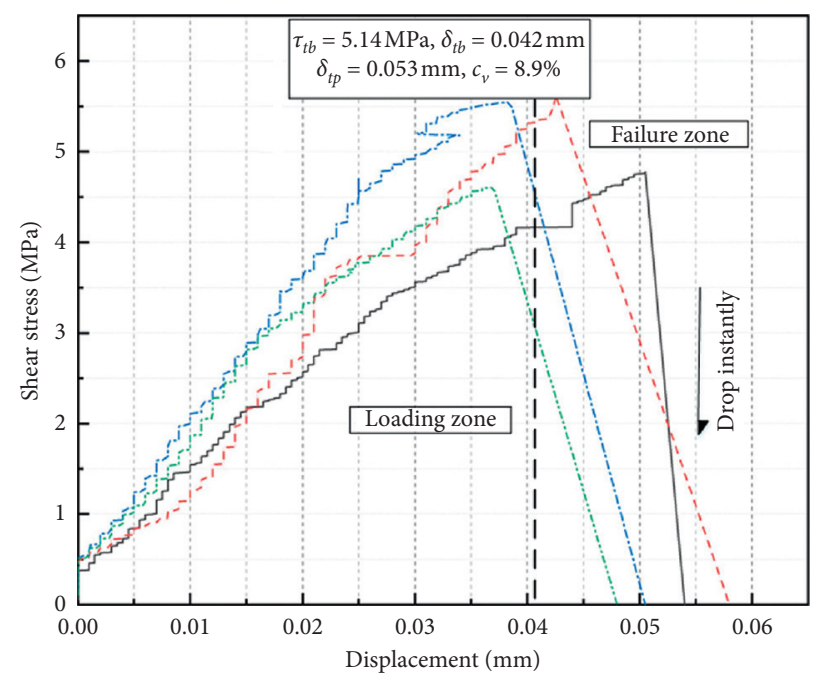

- PS-E-1 $\cdot-\cdot-$ PS-E-3

$\ldots$ PS-E-5

(a)

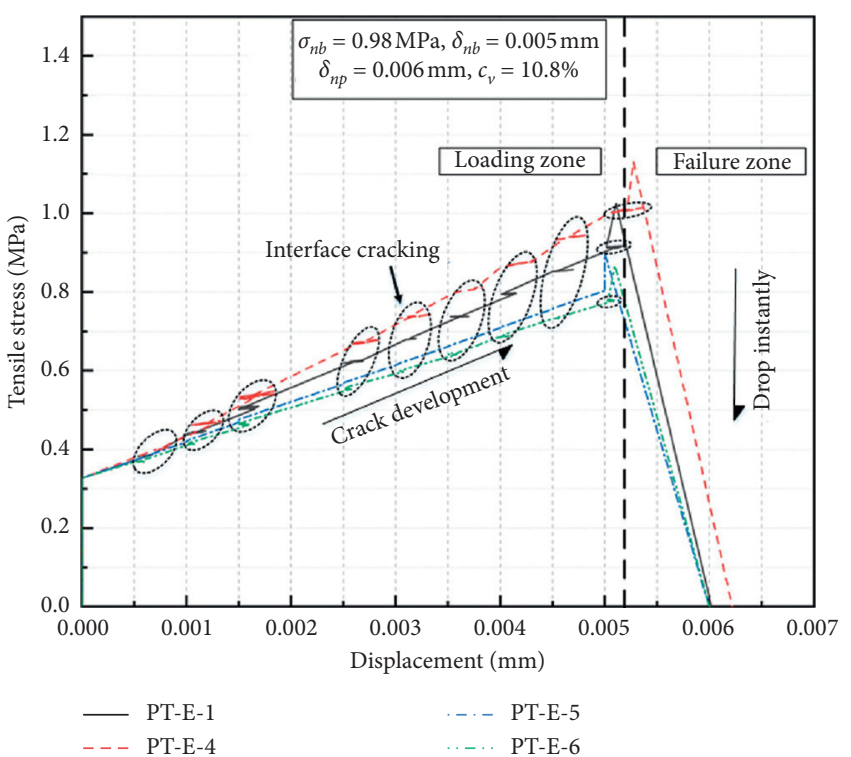

(b)

FIGURE 6: Stress-displacement curves of various specimens in direct shear test and tensile test. (a) The shear stress-displacement curve of specimen PS-E. (b).The tensile stress-displacement curve of specimen PT-E.

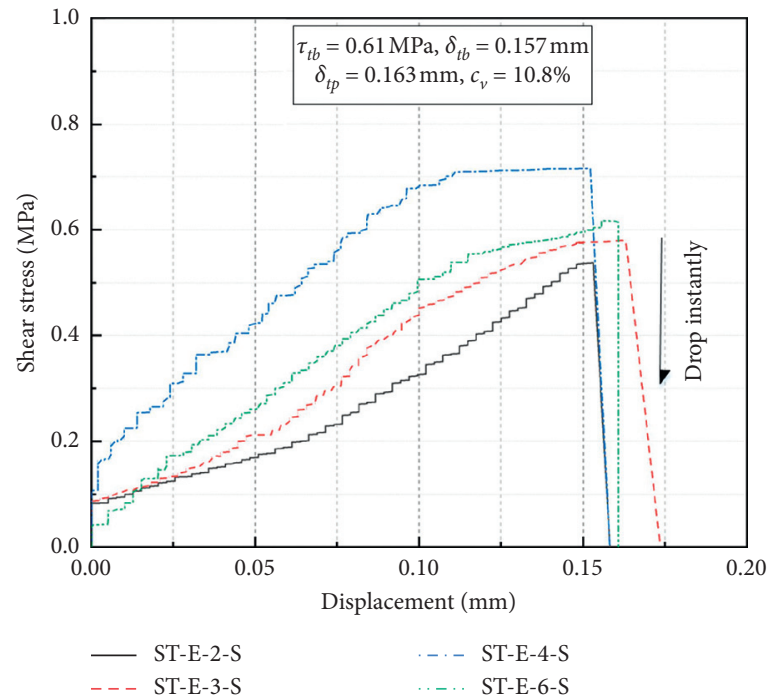

(a)

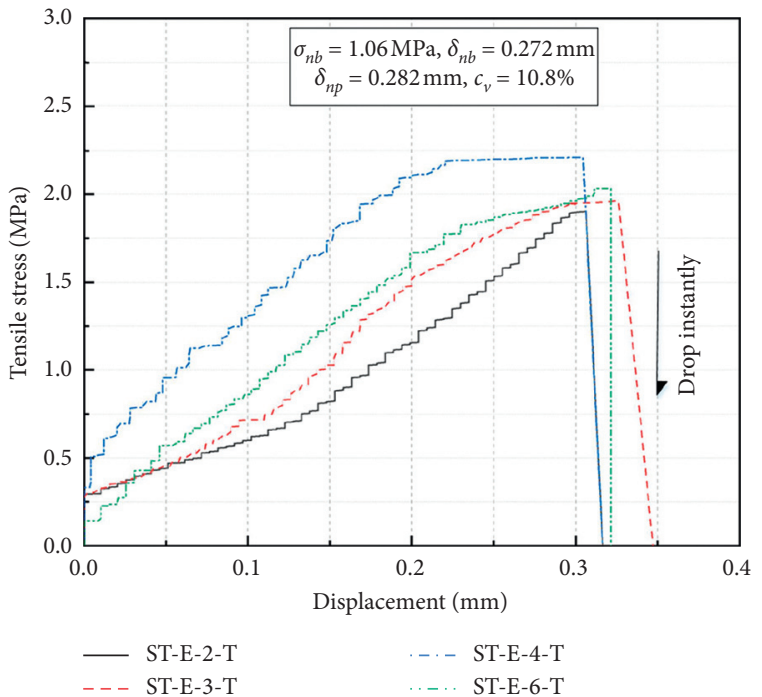

(b)

FiguRE 7: Stress-displacement curves of the interface normal and tangential direction of various specimens in the tensile-shear test. (a) The shear stress-displacement curve of specimen ST-E. (b) The tensile stress-displacement curve of specimen ST-E.

The curve of each specimen was in the form of two broken lines. When the specimens were pulled to the ultimate load in the axial direction, no yield platform appeared in these curves, indicating that the epoxy adhesive interface's normal failure was not ductile. Similarly, based on each specimen's ultimate tensile stress, the entire curve can be divided into the loading zone and failure zone. In the loading area, when the tensile stress was less than $0.27 \mathrm{MPa}$, there was no displacement in the normal direction of each specimen interface, and no cracks developed in the interface. After that, before the ultimate tensile stress, the curve in the area surrounded by the elliptical dotted line began to appear sharp angle and expanded upward with the increase of normal displacement value. According to the interface analysis in Section 3.2, when the epoxy layer was loaded to a particular load, the peeling of the interface and the destruction of the UHPC surface began to appear at the local part of the interface, resulting in the sudden crack of the interface and the vibration of the dial indicator pointer. After the pointer stabilized, the displacement recorded by the dial indicator returned to the displacement value before the local interface cracking, and the dial indicator works normally. 
Because this process was transient, the tensile stressdisplacement curve appeared sharp angle when the interface cracked locally. After that, local cracks in the interface continued to grow until the ultimate tensile stress was reached. At this time, the cracks around the interface shown in Figure 4(a) appeared after the crack is penetrated. The ultimate tensile stress and the corresponding normal displacement of the curve are the average values of each specimen's test results in Table 5, and the calculated coefficient of variation is $10.8 \%$, which was less than $15 \%$. After entering the failure zone, the tensile stress immediately dropped to zero, and the interface failure was brittle. The ultimate displacement value was the average value of each specimen's normal ultimate displacement in Table 5 .

Figure 7 showed the shear and tensile stressdisplacement curves of specimen ST-E-2, ST-E-3, ST-E-4, and ST-E-6. At the beginning of the loading, the stressdisplacement curve increased linearly. When the stress increased to the ultimate stress, the interfacial stress increased slowly, and the interface started to have slight dislocation. Finally, after loading the interface failure, the stress immediately dropped to zero, and the interface behaved as a brittle failure. The results showed that compared with the pure shear and pure tension stress, the interface normal ultimate tensile stress decreased by $10.17 \%$, and the tangential ultimate shear stress was reduced by $88.13 \%$. The shear strength of the prefabricated UHPC-steel epoxy bonding interface decreased obviously under the combined tensile-shear stress, but the tensile strength reduction was not significant.

\section{Numerical Implementation of Interface Constitutive}

4.1. Modeling Scheme. Taking the specimen ST-E as an example, fully understanding the interface failure process and mechanism of the interface under the coupling action of shear and tensile stresses, a numerical model of the prefabricated UHPC-steel epoxy bonding interface is established. The rebar, UHPC, and steel plates of specimen ST-E are simulated using three-dimensional 8-node linear solid elements (C3D8), and the constraint condition between tensile rebar and UHPC is embedded region. In addition to the interface, the other side of the steel plate binding to the UHPC is achieved through "Tie" constraints.

In the existing literature, the steel-concrete interface's numerical simulation method usually adopts the interface element [29, 32]. In this method, the cohesive interface element can accurately simulate the interface with discontinuous displacement and calculate the process of crack initiation and propagation by defining the tractionseparation constitutive response of normal and tangential direction at the interface. The prefabricated UHPC-steel epoxy bonding interface is relatively thin, and the results of three types of tests show that the epoxy layer of the interface is basically not damaged. Take the epoxy layer as the boundary. It is found that the interface failure is concentrated on the side of UHPC, and the E-S interface's bonding performance is reliable. Based on this interface failure characteristic, a zero-thickness cohesive interface element (COH3D8) is introduced into the finite element analysis to simulate the epoxy bonding interface (Figure 8).

4.2. Constitutive Model of Cohesive Interface Element. As shown in Figure 9, bilinear traction-separation constitutive response is applied to the cohesive interface element of zero thickness.

The specific expression is as follows:

$$
t_{n, s, t}= \begin{cases}t_{n, s, t}^{0} \frac{\delta}{\delta_{n, s, t}^{0}}=K_{n, s s, t t} \delta, & \delta \leq \delta_{n, s, t}^{0}, \\ t_{n, s, t}^{0} \frac{\delta_{n, s, t}^{f}-\delta}{\delta_{n, s, t}^{f}-\delta_{n, s, t}^{0}}, & \delta_{n, s, t}^{0}<\delta \leq \delta_{n, s, t}^{f},\end{cases}
$$

where $t_{n}^{0}, t_{s}^{0}$, and $t_{t}^{0}$ are the ultimate strength of the interface, $\delta_{n}^{0}, \delta_{s}^{0}$, and $\delta_{t}^{0}$ are the separation displacement values corresponding to the ultimate strength of the interface, and $\delta_{n}^{f}$, $\delta_{s}^{f}$, and $\delta_{t}^{f}$ are the final crack displacement of the interface.

The above interface parameters are derived from the direct shear test and tensile test in the finite element model. The specific calculation results are shown in Table 6. The fracture energy $\left(G_{n}, G_{s}, G_{t}\right)$ of the whole interface normal and tangential direction is the area surrounded by each broken line in Figure 9(a).

4.3. Constitutive Relation of Materials. As an elastic-plastic material, the damage and cracking behavior of UHPC can be defined by defining CDP (concrete damaged plasticity) model in ABAQUS. In this paper, the tensile constitutive model is based on the stress-strain relationship proposed by Zhang [33], as shown in Figure 10(a). The constitutive model of compression is based on the stress-strain relationship proposed by Yang [34], as shown in Figure 10(b), where $E_{c}$ is the initial elastic modulus and $E_{s}$ is the elastic modulus of secant line at the peak point. In the tensile stress-strain relationship, $f_{c t}$ is $7.2 \mathrm{MPa}, \varepsilon_{c \mathrm{a}}$ is $0.002, \varepsilon_{p c}$ is $0.01, w_{p}$ is 1 , and $p$ is 0.95 . In the compressive stress-strain relationship, $\sigma_{c}$ is $112 \mathrm{MPa}, \varepsilon_{c p}$ is $0.0035, \varepsilon_{c u}$ is $0.01, E_{c}$ is $42100 \mathrm{MPa}$, and $E_{s}$ is $32000 \mathrm{MPa}$. Poisson's ratio of UHPC is 0.2 .

The stress-strain relationship of the steel plate and rebar adopts the linear hardening elastoplastic constitutive model [35] (Figure 10(c)), that is, after the rebar stress reaches the yield stress, the stress increases to the ultimate strength with the increase of the strain. In the stress-strain relationship of the steel plate, $f_{s}$ is $225 \mathrm{MPa}, f_{s u}$ is $370 \mathrm{MPa}, \varepsilon_{s}$ is 0.001 , and $\varepsilon_{s u}$ is 0.009 . In the stress-strain relationship of rebar, $f_{y}$ is $345 \mathrm{MPa}, f_{u}$ is $377 \mathrm{MPa}, \varepsilon_{y}$ is 0.002 , and $\varepsilon_{s u}$ is 0.102 .

4.4. Failure Criteria and Parameters' Study. Irwen [36] divides the interface crack into three models according to different loading directions, namely, open mode (mode I), sliding mode (mode II), and staggered mode (mode III). However, when the interface is in a state of complex stress, the cracks are of two or more mixed cracking models, and the crack propagation is significantly affected by the 


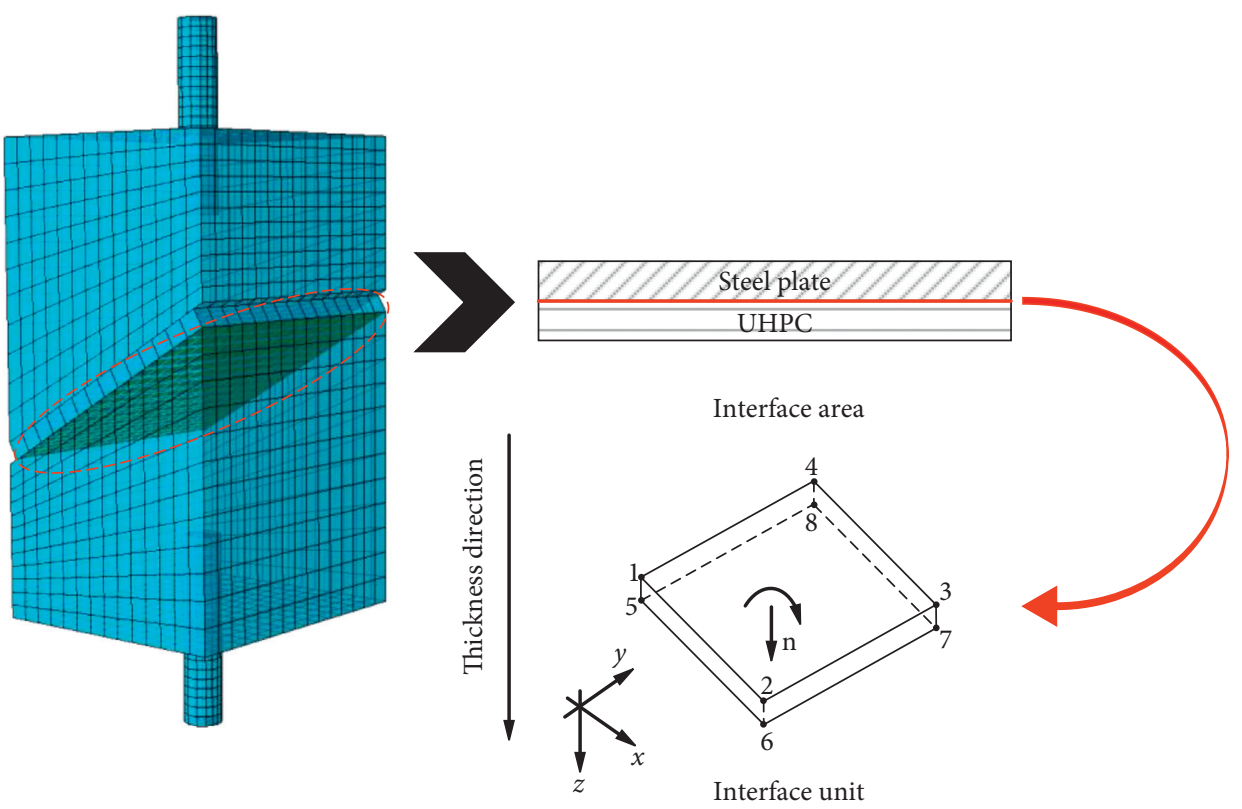

Figure 8: Zero-thickness cohesive interface element (COH3D8).

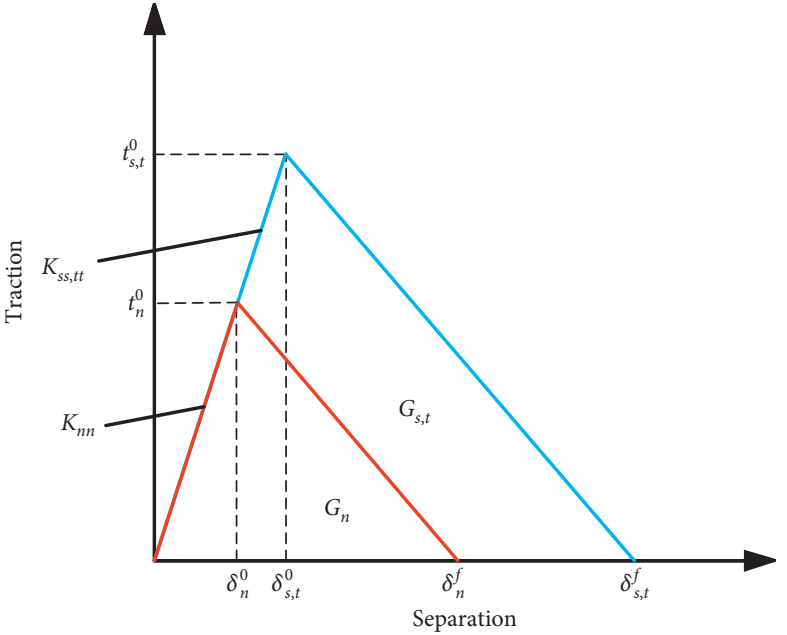

(a)

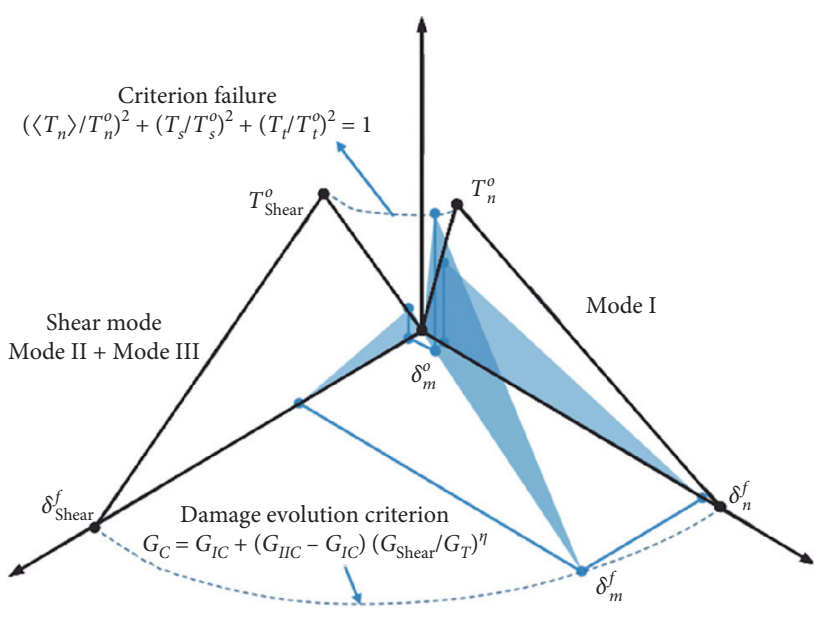

(b)

Figure 9: Constitutive model of the cohesive interface element. (a) Bilinear traction-separation constitutive response. (b) Mixed mode behavior [32].

TABLE 6: Constitutive parameters.

\begin{tabular}{lccc}
\hline Failure mode & $t_{n, s, t}^{0}(\mathrm{MPa})$ & $K_{n n, s s, t t}\left(\mathrm{~N} / \mathrm{mm}^{3}\right)$ & $G_{n, s, t}(\mathrm{~N} / \mathrm{mm})$ \\
\hline Type I & 1.18 & 196 & 0.003 \\
Type II & 5.14 & 122 & 0.136 \\
Type III & 5.14 & 122 & 0.136 \\
\hline
\end{tabular}

interface stress coupling. In order to simulate the crack propagation process of the prefabricated UHPC-steel epoxy bonding interface accurately, the cohesion-analysis method was used in this paper. The cohesive interface element's failure process is mainly divided into two stages:
(1) failure initiation and (2) failure evolution. In the failure evolution stage, the interface element primarily uses the stiffness degradation at the failure initiation stage to simulate the crack growth. The stiffness degradation is mainly controlled by fracture energy's failure criterion and its parameters [37]. In a complex stress state, the relationship of interface failure criterion and unidirectional fracture energy is shown in Figure 9(b). Therefore, this section studies the interface failure criteria and parameters of tensile-shear specimens.

In the figure, $G_{I}$ and $G_{\text {II }}$ are mode I and mode II fracture energies when the interface is completely destroyed. $\alpha$ and $\eta$ are the material constants of power law and BK law, 


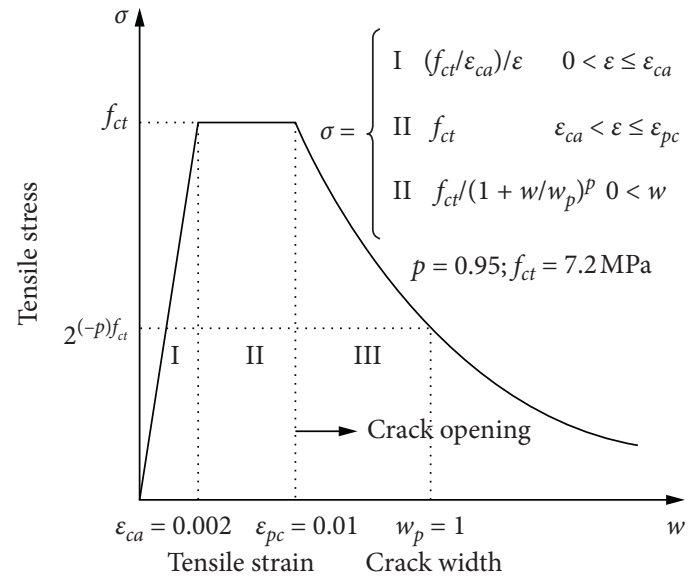

(a)

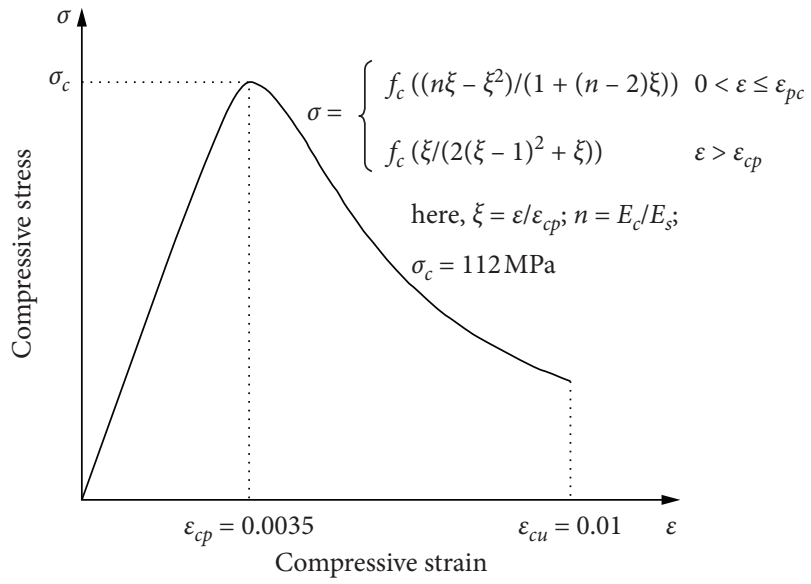

(b)

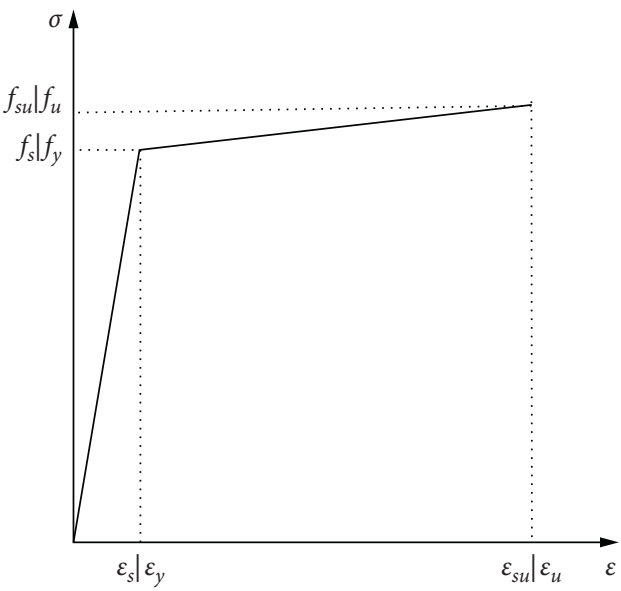

(c)

Figure 10: The constitutive model of UHPC in (a) tension [33], (b) compression [34], and (c) steel plate and rebar [35].

respectively. $\lambda$ is the ratio of mode II fracture energy to mode I fracture energy, which is defined as follows:

$$
\lambda=\frac{G_{\text {II }}}{G_{\text {I }}} \times 100 \%,
$$

It can be seen from Figure 11 when the fracture energy is released by interface failure under pure tension and pure shear state, see Table 6. Compared with, it has significant changes, which shows that, under the state of shear-tension composite stress, the interface's normal fracture energy has been dramatically increased along with the decrease of the tangential fracture energy. The ultimate displacement has been greatly increased, and the normal tangent has a coupling effect. Simultaneously, the specimen's ultimate displacement has been dramatically increased, and the interface has a coupling effect in the normal and tangential directions. In power law, with the increase of $\alpha, \lambda_{\alpha}$ fluctuates in $32 \%-$ $35 \%$, and the maximum and minimum values of normal interfacial and tangential fracture energy are obtained at $\alpha=$ 0.5 and $\alpha=1.5$, respectively. In BK law, $\lambda_{\eta}$ fluctuates from $31 \%$ to $34 \%$ during the growth of $\eta$ from 0.2 to 1.0 . The maximum and minimum values of interfacial normal and tangential fracture energy are obtained at $\eta=0.8$ and $\eta=0.6$. Under the two failure criteria, $\lambda_{\alpha}$ and $\lambda_{\eta}$ are in the range of $31 \%$ to $35 \%$, indicating that, under the state of shear-tension composite stress, the main failure form of interface failure is a tensile failure.

In Figure 12(a), the interfacial fracture energy is the sum of mode I fracture energy and mode II fracture energy. The fracture energy corresponding to the red dotted line is calculated from the test results. It can be seen that the deviation of the fracture energy released in the failure process of specimen ST-E-2 and ST-E-4 is larger than the calculated value, which may be caused by the unsymmetrical rebar center at both ends of the specimen. Therefore, based on the average fracture energy of ST-E-3 and ST-E- 6 , the fracture energy deviation ratios of each parameter to the test are listed, respectively. As shown in the figure, when interface failure follows Power Law, the fracture energy calculated is lower than that corresponding to BK Law, indicating that, under this stress state, the interface stiffness degradation caused by Power Law is faster than that of BK Law, that is, the interface cracking and destruction is faster. It can be intuitively seen that the fracture energy under BK Law deviates too much from the reference value. In contrast, Power Law is closer to the criterion of real interface failure. 


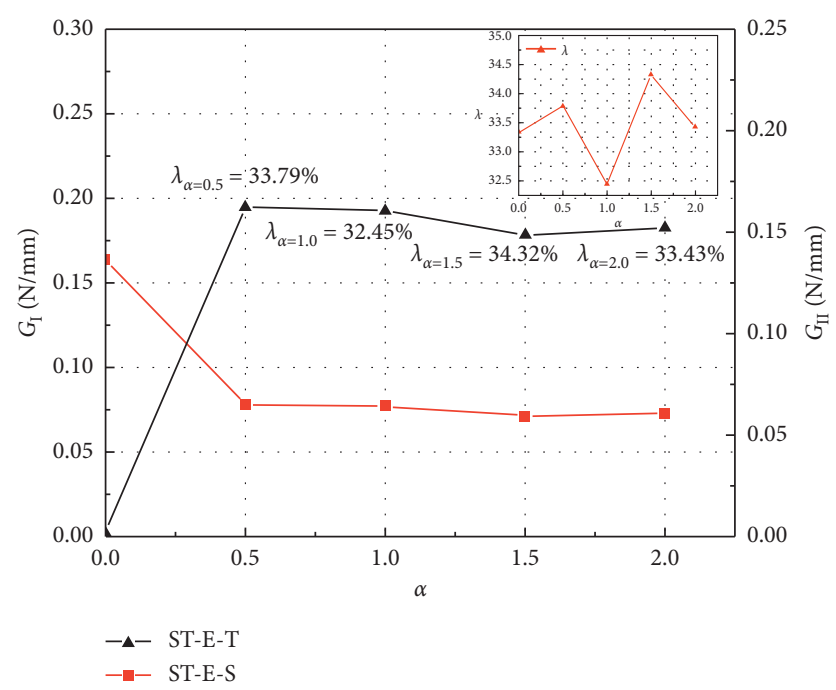

(a)

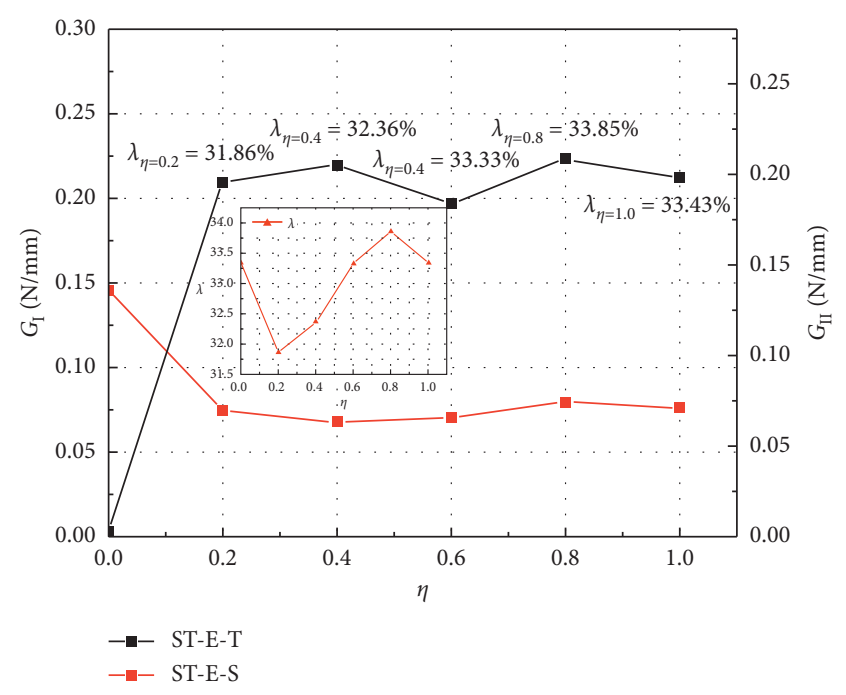

(b)

Figure 11: The influence of interface failure criterion and its parameters on interfacial fracture energy. (a) Power law. (b) BK law.

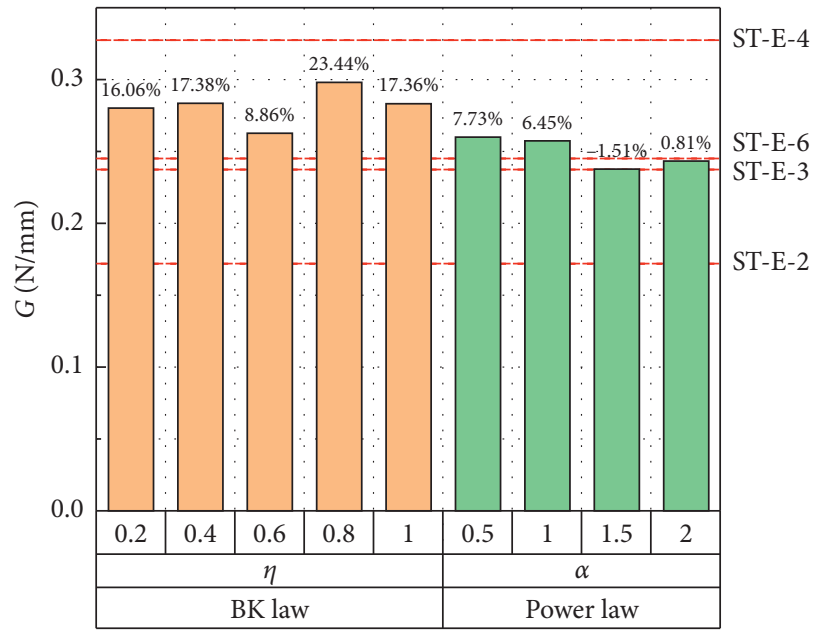

(a)

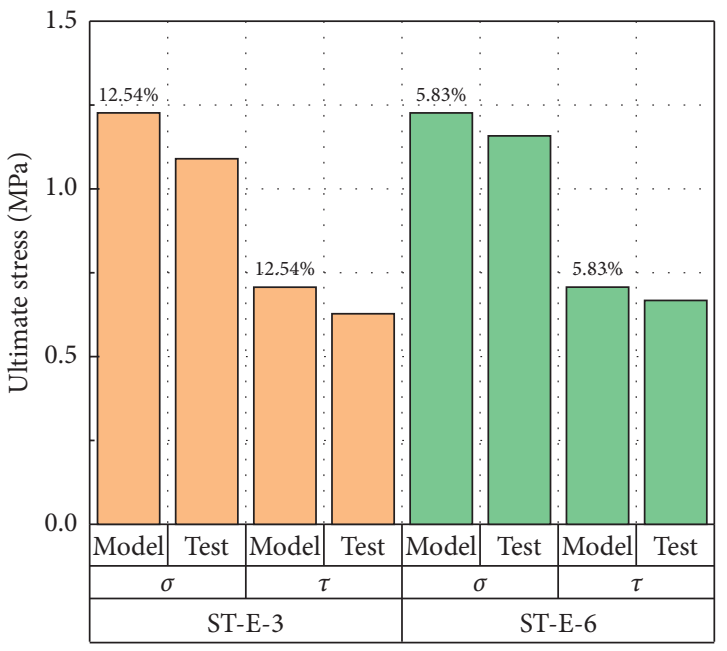

(b)

FIGURE 12: (a) Fracture energy comparison. (b) Interface ultimate stress comparison.

The data shows that when $\alpha=2$, the minimum deviation between the fracture energy and the reference value is $0.81 \%$. Meanwhile, it can be seen from Figure 12(b) that when $\alpha=2$, the ultimate interfacial shear and tensile stress deviations of specimen ST-E-3 and ST-E-6 are 12.54\% and $5.83 \%$, respectively. The difference of ultimate interfacial stress is less than $15 \%$, which shows that the finite element model can simulate the real interface cracking process as much as possible when the material constant $\alpha$ is two in the power law. It is worth noting that the $\lambda$ of each specimen in the experiment is in the range of $33 \%$ to $37 \%$; that is, the interface failure is more inclined to tensile failure, which is consistent with the conclusion of the finite element model.
4.5. Numerical Simulation Results. See Figures 13(a) and 13(b) for the loading process of tensile-shear specimen ST-E-3 and ST-E-6. In the figure, according to the characteristics of the load-displacement curve, the loading to $0.2 \mathrm{P}$ and $0.6 \mathrm{P}$, ultimate load $\mathrm{P}$, and the final failure of the specimen are selected as the research objects, and the whole loading process is divided into the following four stages: (a) crack initiation stage; (b) crack appearance stage; (c) crack growth stage; (d) failure stage. In Figure 13(c), the area reduction rate is used to evaluate the failure process and extent of the specimen interface, which is defined as the percentage of the area $A_{i}$ of interface failure in a particular stage to the interface area $A_{0}$ before loading. The expression is as follows: 


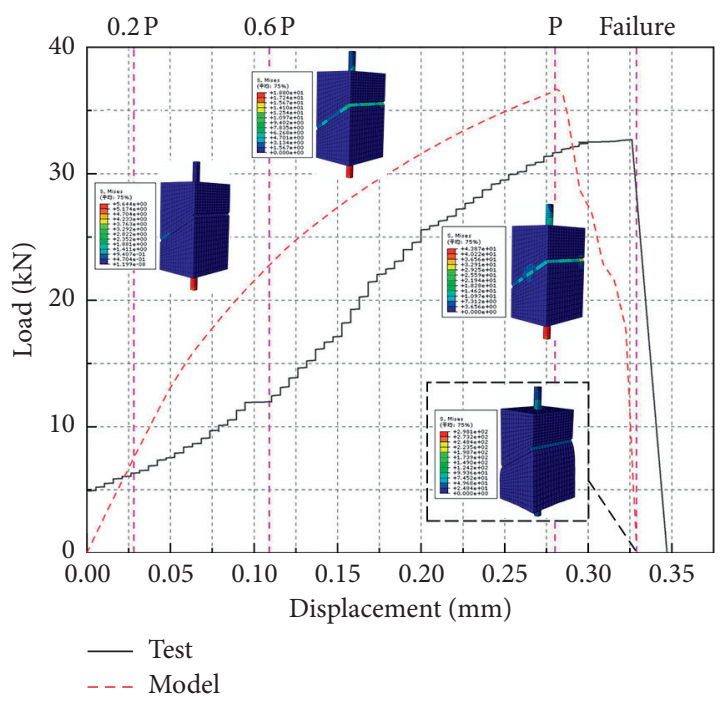

(a)

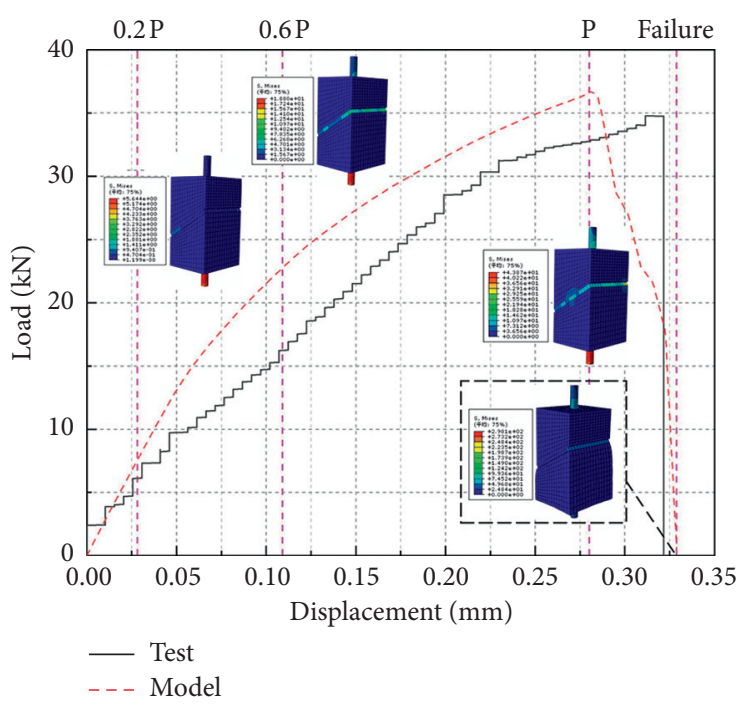

(b)

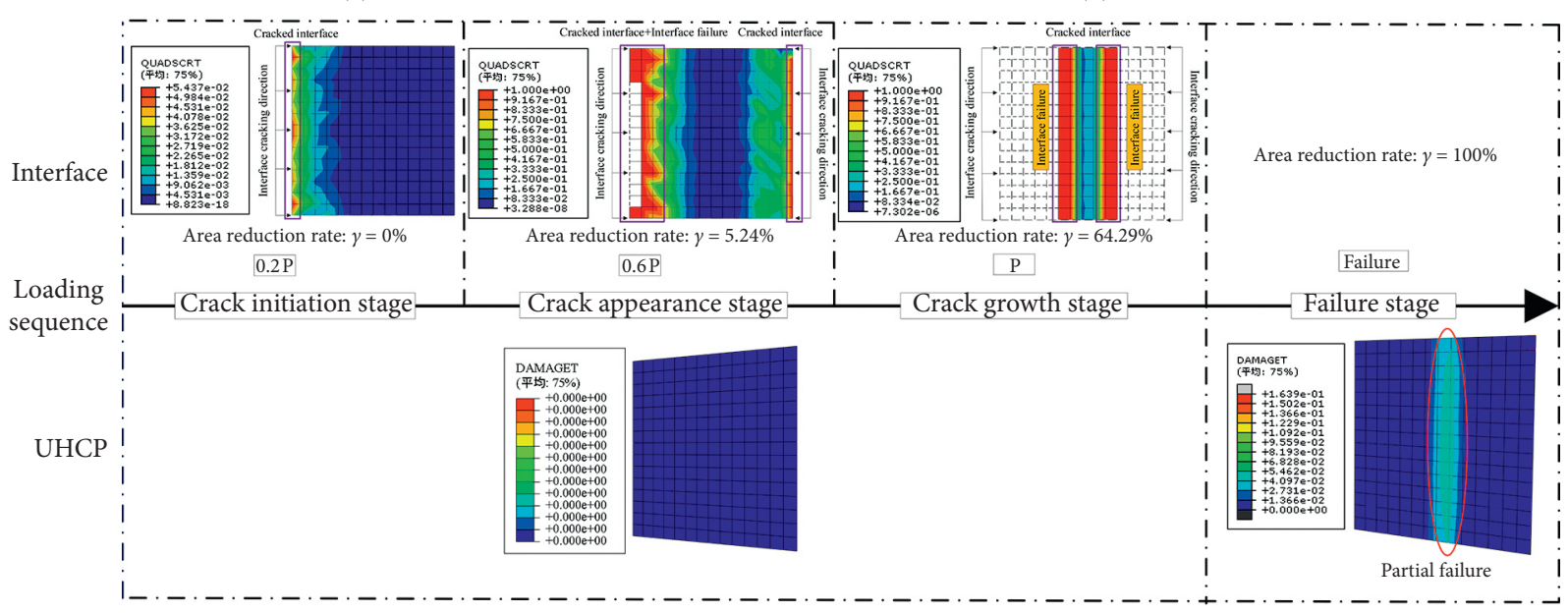

(c)

FIGURE 13: Comparison of experimental and model results. (a) Load-displacement curve of specimen ST-E-3. (b) Load-displacement curve of specimen ST-E-6. (c) Interface crack development and UHPC tensile failure.

$$
\gamma=\frac{A_{i}}{A_{0}} \times 100 \%
$$

During the crack initiation stage, compared with the test results, the slope of the load-displacement curve of the model has a certain deviation, but with the increase of displacement, the stiffness of both of them does not change much. When loading to $0.2 \mathrm{P}$, the specimen's stress is concentrated at the drawing rebar and the interface. The interface end cracks locally, the area reduction rate $\gamma$ is $0 \%$, and the interface does not begin to break. In the crack appearance stage, with the increase of displacement, the curve of the test's curve and the model gradually decreases, and the curve is approximately parallel. The stiffness of the two has the same change rule, but the change is small. When the load reached $0.6 \mathrm{P}$, the stress distribution appears in the upper part of the specimen interface. Cracks appear at both ends of the interface. Along with the interface failure at one end, the interface area reduction rate $\gamma$ is
$5.24 \%$, which indicates that the interface cracking phenomenon is not significant. In the crack growth stage, the slope of the load-displacement curve of the test and model is roughly the same, and the stiffness changes are the same. It can be seen from Figure 12(b) that, at the ultimate load $\mathrm{P}$, the ultimate stress difference between the two is within $15 \%$, and the numerical simulation results are reliable. Compared with the previous stage, the interface area reduction $\gamma$ rate suddenly increases to $64.29 \%$. A large area of interface failure occurs, indicating that the crack expands rapidly during this stage. However, in the first three stages, the numerical results show that UHPC is not damaged by tension, which is different from the test phenomenon. The reason may be that, in fact, near the interface of the specimen, UHPC has no bridging action of the steel fiber, and the strength of the UHPC surface is lower than that of the finite element model; that is, the strength of the UHPC surface was overestimated in the model. Finally, after loading the ultimate load, the specimen's bearing capacity 
decreases rapidly, the interface is completely destroyed, and the UHPC surface is damaged by tension.

\section{Conclusion}

In order to study the static performance of the prefabricated UHPC-steel epoxy bonding interface, this paper carried out a direct shear test, tensile test, and tensile-shear test and obtained the interfacial failure mode, bonding strength, and stress-displacement curve. Based on the constitutive model of a cohesive interface element, a three-dimensional nonlinear finite element model was developed to simulate the mechanical properties of shear-tensile specimens. The main conclusions are summarized as follows:

(1) The shear failure mode of the interface is manifested as E-S interface failure, E-U interface failure, and epoxy layer's localized failure. After all the specimens were compared, it was found that the interface failure mainly occurs at the E-U interface. The normal tensile failure mode shows the peeling of the E-U interface and the destruction of part of the UHPC matrix (the failure of the UHPC's surface). Under the combined action of normal and tangential stress, the interface failure mode is mainly tensile.

(2) In pure shear and pure tension state, the tangential shear strength of the interface was $5.14 \mathrm{MPa}$ and the normal tensile strength was $1.18 \mathrm{MPa}$. Compared with the literature results, the normal tensile strength of the interface is lower, mainly due to the eccentric loading caused by the inaccurate positioning of rebar at both ends of the specimen. Under the combined action of normal and tangential stress, the shear strength decreases by $88.13 \%$, but the tensile strength only reduces by $10.17 \%$, which is not significant.

(3) In pure shear and pure tension state, it can be seen from the stress-displacement curve of the interface that the normal and tangential stress-displacement curve are all presented as a two-fold line. When loading to the ultimate bearing capacity, the normal and tangential ultimate interface displacements are within $0.1 \mathrm{~mm}$. After reaching the ultimate strength, the interface is instantly destroyed without plastic deformation. Under the shear-tensile coupling effect, the displacement has a certain increase. The normal and tangential displacements at the interface are within $0.4 \mathrm{~mm}$, but it is still characterized by brittle failure.

(4) The $\lambda$ of both the model and the test is less than $37 \%$, which shows that the two interface failure modes are consistent; that is, the main failure form of interface failure is a tensile failure. The interfacial tensile-shear failure process can be divided into the following stages: crack initiation stage, crack appearance stage, crack growth stage, and failure stage.[38, 39]

\section{Data Availability}

The data used to support the findings of the study are listed within the article.

\section{Conflicts of Interest}

The authors declare that they have no conflicts of interest.

\section{Acknowledgments}

The authors express their sincere gratitude for the financial support provided by the National Natural Science Foundation of China (52008066 and 51878099), Natural Science Foundation of Chongqing, China (cstc2019jcyj-bshX0067, cstc2019jscx-gksbX0068), Open Project Program of Key Laboratory of Highway Engineering Materials Technology in High-cold and High-altitude Areas, Communications Surveying, Design and Research Institute of T.A.R. (no. HEMTLAB2019B03), and Science and technology projects in T.A.R. (XZ202001ZY0054 G).

\section{References}

[1] L. Ahmed Sbia, A. Peyvandi, P. Soroushian, J. Lu, and A. M. Balachandra, "Enhancement of ultrahigh performance concrete material properties with carbon nanofiber," Advances in Civil Engineering, vol. 2014, Article ID 854729, 10 pages, 2014.

[2] S. Xiang, Y. Gao, and C. Shi, "Synthesis of a new Polycarboxylate at room temperature and its influence on the properties of cement Pastes with different supplementary cementitious materials," Advances in Civil Engineering, vol. 2020, Article ID 8859093, 10 pages, 2020.

[3] S. Yuan, Z. Liu, T. Tong, and C. C. Fu, "A Pilot study on structural responses of normal concrete-UHPC composite bridge decks w/wo rebars through an experimental-numerical approach," Advances in Civil Engineering, vol. 2020, Article ID 8816337, 21 pages, 2020.

[4] Z. Wang, J. Zhou, J. Yang, L. Chen, and W. Wang, "Experiment on the segment model of a plain concrete arch bridge reinforced with UHPC composite arch circle," Advances in Civil Engineering, vol. 2020, Article ID 4015063, 14 pages, 2020.

[5] W. Choi, Y. Choi, and S.-W. Yoo, "Flexural design and analysis of composite beams with inverted-T steel girder with ultrahigh performance concrete slab," Advances in Civil Engineering, vol. 2018, Article ID 1356027, 16 pages, 2018.

[6] S.-K. Kim, W. Kim, and S.-M. Han, "Behavior evaluation of ultrahigh-performance concrete beam containing Paraaramid fibers," Advances in Civil Engineering, vol. 2019, Article ID 5187630, 17 pages, 2019.

[7] Z. Zhang, F. Yang, J.-C. Liu, and S. Wang, "Eco-friendly high strength, high ductility engineered cementitious composites (ECC) with substitution of fly ash by rice husk ash," Cement and Concrete Research, vol. 137, p. 106200, 2020.

[8] Z. Zhang, Q. Zhang, V. C. Li, and Li, "Multiple-scale investigations on self-healing induced mechanical property recovery of ECC," Cement and Concrete Composites, vol. 103, pp. 293-302, 2019.

[9] Z. Zhang, F. Qin, H. Ma, and L. Xu, "Tailoring an impact resistant engineered cementitious composite (ECC) by 
incorporation of crumb rubber," Construction and Building Materials, vol. 262, Article ID 120116, 2020.

[10] J. Liu and R. Guo, "Applications of steel slag powder and steel slag aggregate in ultra-high performance concrete," Advances in Civil Engineering, vol. 2018, Article ID 1426037, 8 pages, 2018.

[11] F. Qin, Z. Zhang, Z. Yin, J. Di, L. Xu, and X. Xu, "Use of high strength, high ductility engineered cementitious composites (ECC) to enhance the flexural performance of reinforced concrete beams," Journal of Building Engineering, vol. 2020, Article ID 101746, 32 pages, 2020.

[12] H. Ma and Z. Zhang, "Paving an engineered cementitious composite (ECC) overlay on concrete airfield pavement for reflective cracking resistance," Construction and Building Materials, vol. 252, Article ID 119048, 2020.

[13] K. Liu, R. Yu, Z. Shui et al., "Optimization of autogenous shrinkage and microstructure for Ultra-High Performance Concrete (UHPC) based on appropriate application of porous pumice," Construction and Building Materials, vol. 214, pp. 369-381, 2019.

[14] C. H. Zhao, "Development of fully prefabricated steel-UHPC composite deck system," Journal of Structural Engineering, vol. 145, no. 7, Article ID 04019051, 2019.

[15] K. Wang, C. Zhao, B. Wu, K. Deng, and B. Cui, "Fully-scale test and analysis of fully dry-connected prefabricated steelUHPC composite beam under hogging moments," Engineering Structures, vol. 197, Article ID 109380, 2019.

[16] Z. Wang, J.-Q. Wang, Y.-C. Tang, T.-X. Liu, Y.-F. Gao, and J. Zhang, "Seismic behavior of precast segmental UHPC bridge columns with replaceable external cover plates and internal dissipaters," Engineering Structures, vol. 177, pp. 540-555, 2018.

[17] Y. Zhang, S. Cai, Y. Zhu, L. Fan, and X. Shao, "Flexural responses of steel-UHPC composite beams under hogging moment," Engineering Structures, vol. 206, Article ID 110134, 2020.

[18] J. Luo, X. Shao, J. Cao, M. Xiong, and W. Fan, “Transverse bending behavior of the steel-UHPC lightweight composite deck: orthogonal test and analysis," Journal of Constructional Steel Research, vol. 162, Article ID 105708, 2019.

[19] Y. Zou, "Partial interaction shear flow forces in simply supported composite steel-concrete beams," Advanced Steel Construction, vol. 14, no. 4, pp. 634-650, 2018.

[20] Y. Zou, "Shear behavior of a novel bearing-shear connector for prefabricated concrete decks," Construction and Building Materials, vol. 7, Article ID 121090, 2020.

[21] S. Zhang, X. Shao, J. Cao, J. Cui, J. Hu, and L. Deng, "Fatigue performance of a lightweight composite bridge deck with open ribs," Construction and Building Materials, vol. 21, no. 7, Article ID 04016039, 2016.

[22] X. ShaoHuang, H. Zhao, B. Chen, and M. Liu, "Basic performance of the composite deck system composed of orthotropic steel deck and ultrathin RPC layer," Journal of Bridge Engineering, vol. 18, no. 5, pp. 417-428, 2013.

[23] B. Yi, C. Meaud, and E. Ferrier, "Non-linear models for steelconcrete epoxy-bonded beams," Journal of Constructional Steel Research, vol. 100, pp. 108-121, 2014.

[24] L. Bouazaoui, G. Perrenot, Y. Delmas, and A. Li, "Experimental study of bonded steel concrete composite structures," Journal of Constructional Steel Research, vol. 63, no. 9, pp. 1268-1278, 2007.

[25] Y. Luo, A. Li, and Z. Kang, "Parametric study of bonded steelconcrete composite beams by using finite element analysis," Engineering Structures, vol. 34, pp. 40-51, 2012.
[26] A. Si Larbi, E. Ferrier, and P. Hamelin, "Concrete to steel lap joint failure criteria under combined shear and peeling stress," Journal of Constructional Steel Research, vol. 65, no. 2, pp. 386-394, 2009.

[27] J. F. Berthet, I. Yurtdas, Y. Delmas, and A. Li, "Evaluation of the adhesion resistance between steel and concrete by push out test," International Journal of Adhesion and Adhesives, vol. 31, no. 2, pp. 75-83, 2011.

[28] Q. Sun, X. Lu, X. Nie, Z. Han, and J. Fan, "Experimental research on tensile and shear behaviour of the interface between non-steam-cured uhpc and steel plate structure," Engineering Mechanics, vol. 34, no. 9, pp. 167-174, 2017.

[29] Z. Wang, X. Nie, J.-S. Fan, X.-Y. Lu, and R. Ding, "Experimental and numerical investigation of the interfacial properties of non-steam-cured UHPC-steel composite beams," Construction and Building Materials, vol. 195, pp. 323-339, 2019.

[30] A. Momayez, M. Ehsani, and A. Ramezanianpour, "Comparison of methods for evaluating bond strength between concrete substrate and repair materials," Cem Concr Res, vol. 35, no. 5, pp. 748-757, 2005.

[31] ASTM, Standard Test Method for Bond Strength of EpoxyResin Systems Used with Concrete by Slant Shear, ASTM, West Conshohocken, PA, USA, 2005.

[32] G. Zhao and A. Li, "Numerical study of a bonded steel and concrete composite beam," Computers \& Structures, vol. 86, no. 19-20, pp. 1830-1838, 2008.

[33] Z. Zhang, X. Shao, W. Li, P. Zhu, and H. Chen, "Axial tensile behavior test of ultra high performance concrete China," Journal of Traffic and Transportation Engineering, vol. 28, no. 8, pp. 50-58, 2015.

[34] J. Yang, Flexural Behavior of Ultra-high Performance Concrete Beams Prestressed with CFRP Tendons, Hunan University, Changsha, China, 2007.

[35] Ministry of Housing and Urban-Rural Development of the People's Republic of China, Code for Design of Concrete Structures (GB 50010-2010), China Planning Press, Beijing, China, 2015.

[36] G. R. Irwin, Handbuch der Physik, Springer-Verlag, BerlinHeidelberg, 1958.

[37] D. Ranz, J. Cuartero, L. Castejon, R. Miralbes, and H. Malon, "A cohesive zone model approach to interlaminar behaviour of carbon/epoxy laminated curved beams," Composite Structures, vol. 238, Article ID 111983, 2020.

[38] P. Buitelaar, "einforced high performance concrete overlay system for steel bridges," in Proceedings of the 5th International CROW Workshop On Fundamental Modelling of the Design and Performance of Concrete Pavements, Istanbul, Turkey, April, 2004.

[39] J.-T.. W. Zhou, Zong-Shan, and J. Yang, "Experimental study on axial compression of hollow ultra high performance concrete short columns," Bridge Construction, vol. 49, no. 2, pp. 52-56, 2019. 